\title{
Effect of long term treatment with metoprolol and sotalol on ventricular repolarisation measured by use of transoesophageal atrial pacing
}

\author{
CARINA BLOMSTRÖM-LUNDQVIST, MICHAL DOHNAL, ISAAC HIRSCH, \\ ANETTE LINDBLAD, AKE HJALMARSON, S BERTIL OLSSON, \\ NILS EDVARDSSON \\ From the Division of Cardiology, Medical Department I, Sahlgren's Hospital, S-413 45 Gothenburg,
Sweden
}

SUMMARY The effects of long term (4 weeks) treatment with oral metoprolol ( $100 \mathrm{mg}$ twice daily) and sotalol ( $160 \mathrm{mg}$ twice daily) on ventricular repolarisation time were compared in a double blind crossover study in 20 patients post-infarction. For QT interval studies transoesophageal atrial pacing was performed at a cycle length of $800 \mathrm{~ms}$. Sotalol prolonged the QT interval by 5-7\% compared with metoprolol. The prolongation reflects a change in the repolarisation time because there was no change in the QS interval. Measurements of heart rate at rest and during bicycle exercise indicated that metoprolol and sotalol in the doses selected were equipotent as beta blockers. Transoesophageal atrial pacing is a simple non-invasive method with few and mild side effects that is well suited to drug studies.

According to the Vaughan Williams classification, beta adrenergic receptor antagonists have class II antiarrhythmic properties that are characterised by a reduction of the spontaneous phase 4 depolarisation of pacemaker cells. ${ }^{1}$ Some beta blockers, for example alprenolol and propranolol, also have a direct membrane stabilising (class I) effect that leads to a reduction in the maximum rate of rise of cardiac action potentials. ${ }^{1}$ This antiarrhythmic effect has been seen when high concentrations of such drugs are used in vitro, but it is believed to be of no clinical importance. ${ }^{2} 3$

Metoprolol is a cardioselective beta blocker which has no intrinsic sympathomimetic activity and membrane stabilising properties. ${ }^{4}$ Sotalol is a noncardioselective beta blocker that has no important membrane stabilising or intrinsic stimulatory activity. ${ }^{15}$ In contrast to other currently available beta blockers, sotalol has class III antiarrhythmic activity in that it increases the duration of the action potential after short term administration. ${ }^{67}$ Some beta blockers including metoprolol have caused similar effects but only after long term treatment and to a lesser degree. Although recent studies in man have

Requests for reprints to Dr Carina Blomström-Lundqvist, Division of Cardiology, Medical Department I, Sahlgren's Hospital, S-413 45 Gothenburg, Sweden.

Accepted for publication 27 September 1985 suggested that sotalol and other currently available beta blockers may have different effects on ventricular repolarisation after long term treatment as far as we know no double blind study has been performed to confirm this. ${ }^{89}$ Craemer et al performed a randomised crossover study but this was not double blind. ${ }^{10}$

We have compared the effects of long term treatment with metoprolol (class II) and sotalol (classes II and III) on ventricular repolarisation in a double blind crossover study in patients who were already on chronic beta blocker treatment after a previous myocardial infarction. We used doses of metoprolol ( $100 \mathrm{mg}$ twice daily) and sotalol (160 mg twice daily) with equipotent beta blocking effects.

\section{Patients and methods}

We studied 20 men aged 46-64 years (mean 60 years) who had had a myocardial infarction more than one year before. They were on long term metoprolol treatment (minimum daily dose of $150 \mathrm{mg}$ ). None was on any other antiarrhythmic agent. We excluded patients with clinical signs of heart failure or severe angina (New York Heart Association functional class III-IV) and those with either partial or complete bundle branch block. To ensure measurable QT intervals we did not study patients with biphasic negative $T$ waves or $U$ waves in the surface lead V2. The 
study protocol was approved by the ethical committee of the hospital, and each patient gave informed oral consent.

\section{METHODS}

In this double blind crossover study the patients remained on their usual long term treatment with metoprolol during the run-in period. They were randomly allocated to receive oral sotalol $160 \mathrm{mg}$ twice daily (10 patients) or metoprolol $100 \mathrm{mg}$ twice daily (10 patients) for four weeks (period I). After this they were switched to treatment with the other tablet for another four weeks (period II). Investigations were performed during the run-in period and after both periods of treatment.

\section{ERGOMETER TEST}

The patients underwent a bicycle ergometer test starting at a workload of $50 \mathrm{~W}$ which was increased by $10 \mathrm{~W}$ per minute. Heart rate, blood pressure, and a 12 lead electrocardiogram were monitored each minute. When the heart rate reached $70 \%$ of the predicted maximum pulse rate the exercise test was stopped. The effect of the beta blockade was evaluated and compared by measurement of heart rates at rest and during exercise.

TRANSOESOPHAGEAL ATRIAL PACING

With the patient in a semirecumbent position, that is lying at approximately $40^{\circ}$ to the horizontal, a bi- polar electrode catheter was advanced into the distal oesophagus. We used flexible silicone rubber coated bipolar electrode catheters with an interelectrode distance of 18 or $28 \mathrm{~mm}$ (Medtronic 6992). The distal electrode was designated as the negative (cathode) electrode. Unipolar atrial electrograms were recorded from the catheter (Fig. 1a). The electrode position was adjusted to obtain a maximum positive unipolar atrial deflection from the distal electrode and a biphasic atrial electrogram from the proximal electrode. The minimum threshold current required to pace the atria reliably was determined by a technique described elsewhere. ${ }^{11} \mathrm{~A}$ burning sensation causing slight epigastric discomfort was common during stimulation, but no sedative or other premedication was required. Transoesophageal bipolar atrial stimulation was undertaken for approximately three minutes at a basic cycle length of $800 \mathrm{~ms}$ (Fig. 1b). Atrial stimulation was performed with a programmable stimulator made in our own laboratory that delivers a constant current square-wave pulse. The pulse width was fixed at $10 \mathrm{~ms}$. A precordial electrocardiogram was displayed on an oscilloscope and recorded on a Mingograph 82 (Siemens-Elema) as well as on a tape recorder (TEAC) during atrial stimulation.

\section{BLOOD SAMPLING}

Blood samples were collected immediately after the investigations for later analyses of plasma concen- (a)

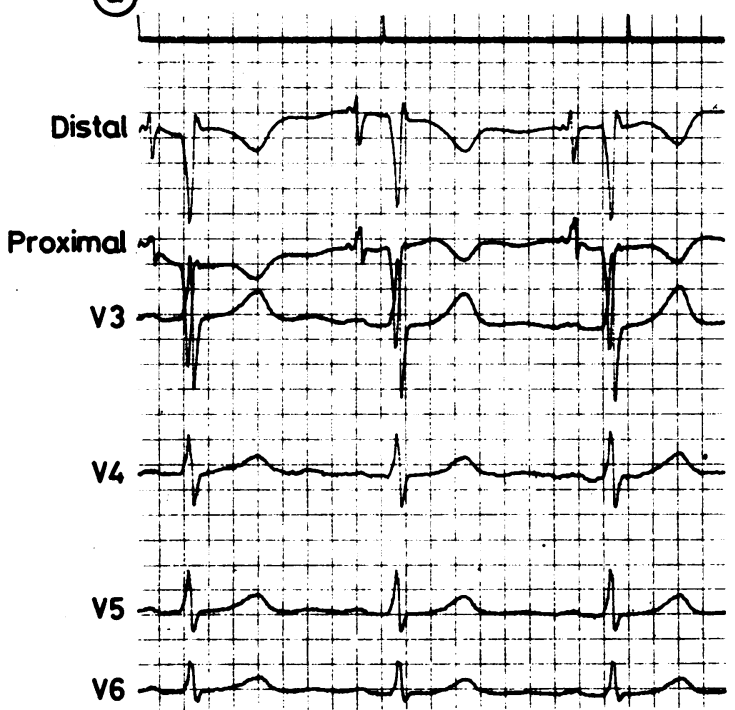

(b)
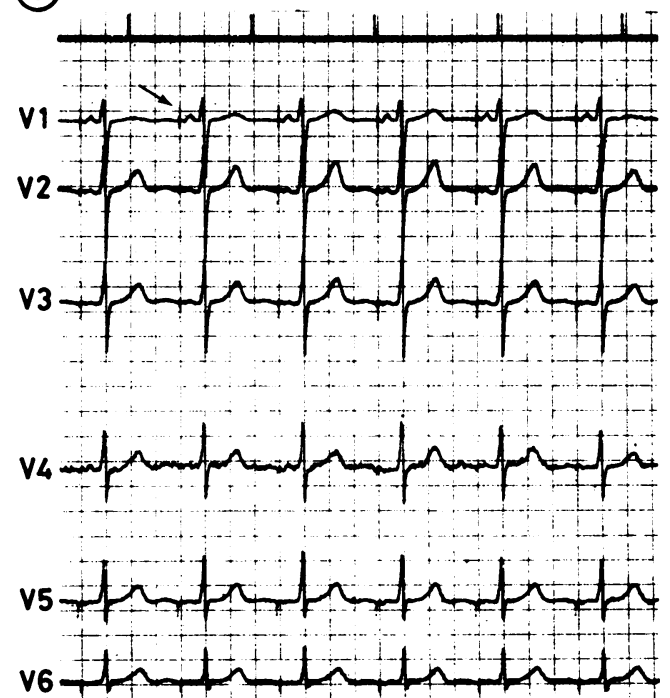

Fig. 1 (a) A representative example of unipolar atrial electrograms recorded from the oesophageal electrode catheter. Paper speed $50 \mathrm{~mm} / \mathrm{s}$. (b) Recording of transoesophageal bipolar atrial pacing from the same patient as in (a). Atrial stimulation was performed at a basic cycle length of $800 \mathrm{~ms}$. The arrow indicates the stimulus spike. Paper speed $25 \mathrm{~mm} / \mathrm{s}$. 


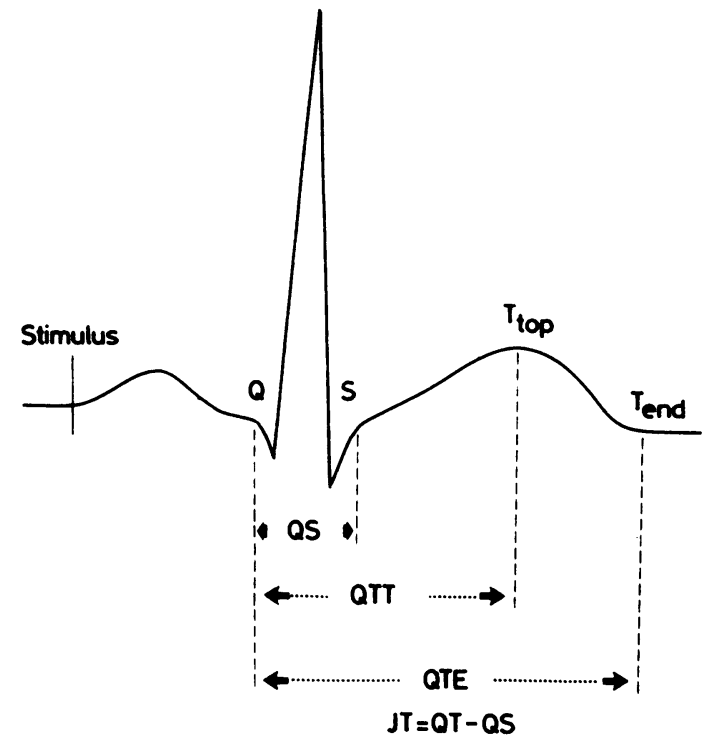

Fig. 2 The following intervals were analysed: $Q S$ (from the beginning of the $Q$ wave to the end of the $S$ wave), $Q T T$ (from the beginning of the $Q$ wave to the top of the $T$ wave), and $Q T E$ (from the beginning of the $Q$ wave to the end of the $T$ wave). The $\mathcal{F T}$ interval was calculated by subtracting the $Q S$ interval from the $Q T$ interval. All intervals were measured at a paper speed of $100 \mathrm{~mm} / \mathrm{s}$.

trations of metoprolol and sotalol.

\section{COMPUTERISED ANALYSIS OF THE QRST} INTERVALS

We used a specially developed interactive computer program to analyse the following variables: $Q S, Q T$ top, QT end, JT top, and JT end (as defined in Fig. 2). All measurements were made from lead V2 (except for one patient where V3 was used because of lack of signal). The intervals were all measured at a fixed basic atrial pacing cycle length of $800 \mathrm{~ms}$. A representative sample of each recording saved on tape was displayed on the oscilloscope. For the first beat chosen, the operator defined the following seven points: start of the pacemaker stimulus, start of the $Q$ wave, top of the $R$ wave, negative top of the $S$ wave, end of the $S$ wave, top of the $T$ wave, and end of the $T$ wave. For the subsequent analysed beats these points were outlined by the program but could be corrected if necessary. Only signals that were preceded by constant and adequate pacing were analysed. All the results are the means of at least five representative complexes. The output consisted of a table of each individual variable for all accepted beats as well as the mean values and standard deviations.
QTC CALCULATION

QTc is usually calculated by the Bazett formula from the QT interval measured during sinus rhythm. In the present study the QTc was calculated from the QT intervals measured during transoesophageal atrial pacing at a basic cycle length of $800 \mathrm{~ms}$.

\section{STATISTICAL METHODS}

We used the two-tailed Student's $t$ test to compare paired differences. The level of statistical significance was set at a $p<0.05$, but all $p$ values are given.

\section{Results}

Fifteen out of 20 patients were included in the QT interval analysis. The reasons for exclusion were as follows: one patient was excluded during run-in because he developed hypotension, sweating, and dizziness and slight bradycardia when transoesophageal atrial pacing was started. The symptoms and physical findings were observed shortly after pacing was started, and stimulation was discontinued before reliable atrial pacing could be obtained. The patient reported no pain. Blood pressure returned to normal after the patient was tilted in the head down position. In another patient an intolerable headache developed during blind period 1 (sotalol) and the medication was discontinued after 11 days. Three patients had biphasic negative $T$ waves or prominent $U$ waves in one or more recordings that made subsequent comparisons of QT intervals impossible. They completed the study but were excluded from QT interval analyses.

Thus atrial pacing was performed without side effects in 18 of 19 patients on three consecutive occasions. The means of the thresholds for adequate pacing were: $19 \mathrm{~mA}$ (run-in), $21 \mathrm{~mA}$ (metoprolol), and $22 \mathrm{~mA}$ (sotalol) (range 7-36 mA).

\section{HEART RATE}

The heart rates at rest and during exercise (measured at a workload of $100 \mathrm{~W}$ ) were not significantly different on the two treatments (Table). This indicates that a similar degree of beta blockade was induced by the two agents.

\section{QS INTERVALS}

There was no significant change in the QS interval, which was within the normal range (Table) on both agents.

\section{QTT AND QTE INTERVALS}

Treatment with sotalol was associated with a significantly longer QTT interval than treatment with metoprolol (mean (SD)) (319 (18) ms vs 301 
Table Comparisons of heart rate and QRST intervals (ms) during run-in and after 4 weeks' treatment with metoprolol or sotalol

\begin{tabular}{|c|c|c|c|c|c|c|c|c|}
\hline Results & Run-in & $M$ & $S$ & $\begin{array}{l}\text { Mvs run-in } \\
\text { (p) }\end{array}$ & $\begin{array}{l}\text { Svs run-in } \\
\text { (p) }\end{array}$ & $\begin{array}{l}\text { Sos run-in } \\
\text { (\% change) }\end{array}$ & $\begin{array}{l}\text { Ses } M \\
(p)\end{array}$ & $\begin{array}{l}\text { Sos } M \\
(\% \text { change })\end{array}$ \\
\hline $\begin{array}{l}\text { Heart rate at rest (bpm) } \\
\text { Heart rate at } 100 \mathrm{~W}(\mathrm{bpm}) \\
\text { QS } \\
\text { QT top } \\
\text { QT end } \\
\text { JT top } \\
\text { JT end } \\
\text { QTc top } \\
\text { QTc end }\end{array}$ & $\begin{array}{l}58(16) \\
96(20) \\
98(12) \\
300(11) \\
421(17) \\
202(16) \\
324(24) \\
330(10) \\
470(20)\end{array}$ & $\begin{array}{l}55(8) \\
92(11) \\
99(11) \\
301(16) \\
414(25) \\
202(19) \\
316(26) \\
340(20) \\
460(30)\end{array}$ & $\begin{array}{l}57(10) \\
95(14) \\
100(9) \\
319(18) \\
436(25) \\
219(23) \\
336(28) \\
360(20) \\
490(30)\end{array}$ & $\begin{array}{l}\text { NS } \\
\text { NS } \\
\text { NS } \\
\text { NS } \\
\text { NS } \\
\text { NS } \\
\text { NS } \\
\text { NS } \\
\text { NS }\end{array}$ & $\begin{array}{l}\text { NS } \\
\text { NS } \\
\text { NS } \\
<0.001 \\
<0.001 \\
<0.001 \\
<0.005 \\
<0.001 \\
<0.005\end{array}$ & $\begin{array}{l}- \\
- \\
+6 \\
+4 \\
+8 \\
+4 \\
+9 \\
+4\end{array}$ & $\begin{array}{l}\text { NS } \\
\text { NS } \\
\text { NS } \\
<0.001 \\
<0.001 \\
<0.001 \\
<0.001 \\
<0.001 \\
<0.001\end{array}$ & $\begin{array}{l}- \\
- \\
+6 \\
+5 \\
+8 \\
+6 \\
+6 \\
+7\end{array}$ \\
\hline
\end{tabular}

Run-in, long term treatment with metoprolol at a minimum daily dose of $150 \mathrm{mg} ; \mathrm{M}$, after four weeks' treatment with metoprolol $(100 \mathrm{mg} \times 2)$; $\mathrm{S}$, after four weeks' treatment with sotalol $(160 \mathrm{mg} \times 2)$.

(16) $\mathrm{ms},+6 \% ; \mathrm{p}<0.001)$. Sotalol also prolonged the QTE interval (436 (25) ms vs 414 (25) $\mathrm{ms},+5 \%$, p $<0.001$ ) (Table and Fig. 3).

QTc

We used Bazett's formula to calculate the QTc from the QT intervals measured during atrial pacing. The QTc top was 340 (20) ms during metoprolol and 360 (20) ms during sotalol treatment $(p<0.001)$. The QTc end was 460 (30) ms (metoprolol) and 490 (30) ms (sotalol) $(\mathrm{p}<0.001)$ (Table).

JTT AND JTE INTERVALS

The JTT and JTE intervals increased by $8 \%$ and
$6 \%$ respectively $(\mathrm{p}<0.001)$ during treatment with sotalol compared with metoprolol (Table).

\section{PLASMA CONCENTRATIONS}

The plasma concentration of metoprolol in 15 samples about five hours after one oral dose was 41-700 $\mathrm{nmol} / \mathrm{l}$ (mean $265 \mathrm{nmol} / \mathrm{l}$ ). The plasma concentration of sotalol in 14 samples was $0.8-2.0 \mu \mathrm{g} / \mathrm{ml}$ (mean 1.4 $\mu \mathrm{g} / \mathrm{ml})$. One sample was lost.

\section{Discussion}

The antiarrhythmic efficacy of beta blockers may be the result of their ability to oppose the effects of (a)
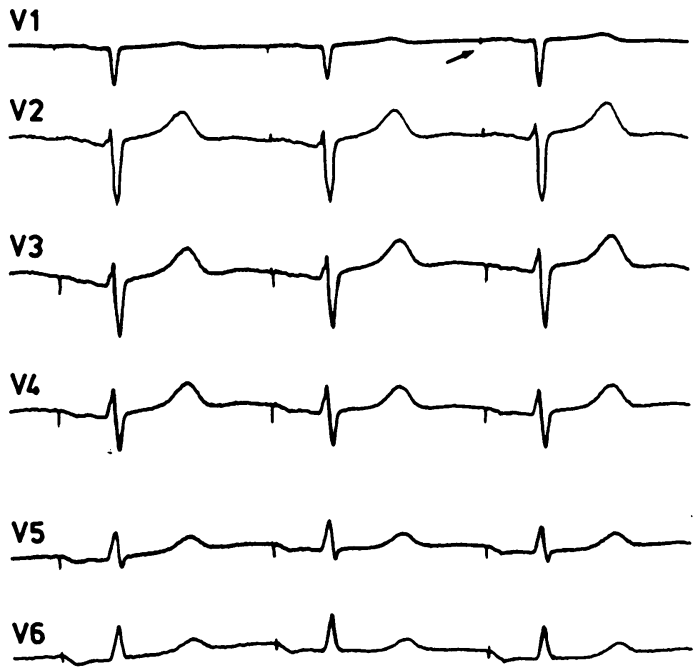

(b)
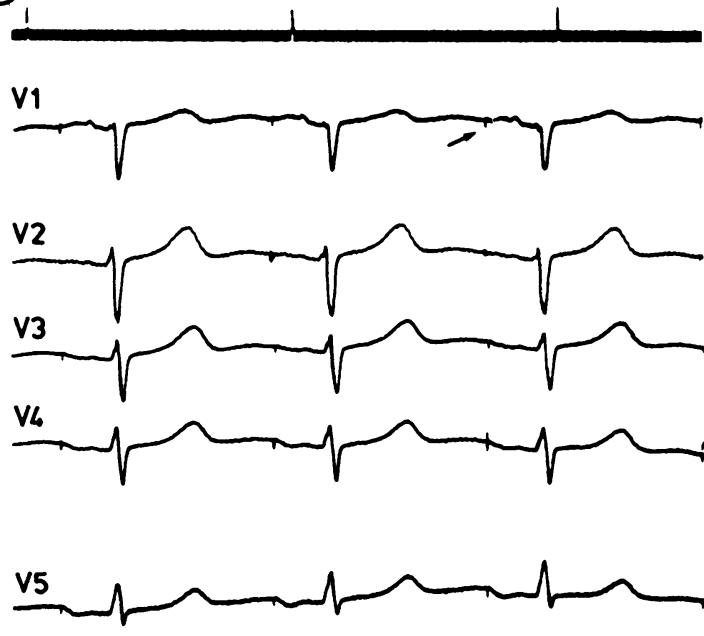

V6

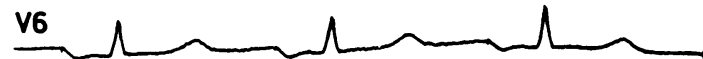

Fig. 3 Electrocardiograms obtained during atrial pacing from one patient. They show the $Q T$ intervals during treatment with metoprolol $(a)$ and sotalol (b). The arrow indicates the stimulus spike. Paper speed was $50 \mathrm{~mm} / \mathrm{s}$. 
catecholamines on automaticity and conductivity. Animal studies have shown that several beta blocking agents with different pharmacological properties produce a moderate prolongation of the ventricular repolarisation time when they have been given for four weeks. ${ }^{1213}$ This contrasts with that lack of effect after short term administration. In healthy volunteers metoprolol prolonged the right ventricular repolarisation time by $6-8 \%$ after five weeks' treatment with $400 \mathrm{mg}$ daily; short term administration of metoprolol had no effect. ${ }^{9}$

In contrast, short term administration of sotalol, which was initially described as a pure beta adrenergic antagonist with class II activity, considerably increased the action potential duration. ${ }^{67}$ This class III mode of action was recently confirmed in patients with atrial fibrillation. Sotalol prolonged the right ventricular repolarisation time by about $13-17 \%$ after intravenous administration of $100 \mathrm{mg}$, and this effect was maintained after twelve weeks of oral treatment. $^{8}$ This is consistent with other reports demonstrating a prolongation of QT and JT intervals after short term administration of sotalol. ${ }^{14}$ The mechanism by which beta adrenergic blockers such as metoprolol prolong the ventricular repolarisation time after chronic treatment is not yet known. It has been proposed that this effect represents a myocardial adaptation to prolonged beta blockade. ${ }^{15}$

In order to clarify whether long term treatment with a beta blocker without class III activity would prolong the ventricular repolarisation time to the same extent as an antiarrhythmic agent with combined class II and III activity, it seemed logical to use sotalol as a standard for comparison. The ventricular repolarisation time may be assessed from the QT intervals, ventricular effective refractory periods, and ventricular monophasic action potentials. Recent studies with beta adrenergic blockers have shown consistent changes in these indices after long term treatment. ${ }^{9}$

Difficulties with defining the end of the $T$ wave make measurement of the QT interval uncertain. ${ }^{16}$ To ensure more easily defined intervals we also included the QT top interval. The QT interval is frequency dependent and the most widely applied rate correction factor has been Bazett's formula. The formula was intended to correct the values to a heart rate of 60 beats per minute, but will give an overcorrection of the QT interval at high rates and an undercorrection at low heart rates. When Bazett's formula is used for correction during sinus rhythm, slight or even moderate drug induced changes might therefore be masked, as they were in other drug studies. ${ }^{17}$ If, however, the heart rate is kept constant, the measurements will contain a systematic error but will allow drug induced changes to be detected. To circumvent the use of a correction factor some previous studies have compared QT intervals at identical and constant paced heart rates by means of intracardiac atrial stimulation. ${ }^{10} 17$

To ensure the detection of even minor drug induced changes and to avoid an invasive intervention, we have compared QT intervals at a fixed paced heart rate produced by transoesophageal atrial stimulation. We performed transoesophageal atrial pacing on 56 different occasions and on only one $(1 \cdot 8 \%)$ occasion was there a complication, judged to be a vasovagal reaction.

The electrode catheter insertion depth is carefully controlled to minimise the pacing threshold and the appropriate depth may be predicted by the site of the maximum atrial electrogram or the patient's height. ${ }^{11}$ In the present study, the threshold for adequate atrial pacing was found in most patients when the atrial electrogram from the proximal electrode showed a biphasic deflection and the distal electrode a highly positive atrial deflection, and this accords with other studies. ${ }^{11}$ The mean minimum pacing threshold was of about the same magnitude for all three pacing sequences in the same patient when pacing was performed from identical positions.

The minimum current required for atrial pacing varies among different investigators. In one study, atrial capture was achieved in $75 \%$ of the attempts when a current of $17.5 \mathrm{~mA}$ was used. ${ }^{18}$ Others have reported an average minimum pacing threshold of 10 $\mathrm{mA}$ (range 4.5-20 mA). ${ }^{11}$ The minimal thresholds obtained in the present study were somewhat higher than those reported by other investigators, but no patient complained of intense discomfort. The currents used in this study were considerably below those reported to produce hyperaemia or epithelial erosion in canine experiments. ${ }^{1920}$ Epithelial erosion appeared after pacing at $60 \mathrm{~mA}$ at a pulse width of $2 \mathrm{~ms}$ for 4 hours, but no injury was noted when the pacing time was limited to $<30$ minutes.

We found that four weeks' treatment with sotalol significantly prolonged the QT intervals by $5-7 \%$ more than metoprolol (Table). The prolongation was confined to the JT interval, as there was no significant difference in the QS interval, and this must therefore reflect a change in the ventricular repolarisation time. This is consistent with results from other studies, although the groups of patients studied were not comparable. ${ }^{8921}$ The QT top and the QT end intervals showed consistent changes, which suggests that the former may be used with advantage, especially when the end of the $T$ wave is obscured. The QTc showed similar and statistically significant changes when calculated from a fixed paced heart rate. The QTc was not calculated during sinus rhythm. The heart rates at rest and the heart 
rates during exercise were not significantly different on the two treatments, hence the difference in the repolarisation time cannot be attributed to unequal beta blockade.

Even though long term administration of various beta blockers may result in a class III like mode of action, this study and those of others indicate a quantitative difference between these agents and sotalol. Unlike metoprolol, sotalol significantly and selectively prolonged ventricular refractoriness in infarcted zones compared with normal myocardium after short term administration in dogs. ${ }^{22}$ In the same study sotalol significantly prevented and slowed ventricular arrhythmias in ischaemic myocardium; metoprolol did not have this effect. Whether this effect is due to the class III property of sotalol or to other differences (beta ${ }_{2}$ blockade) is not known.

In conclusion, sotalol significantly prolonged the QT interval by $5-7 \%$ compared with metoprolol after four weeks' treatment. The prolongation reflects a change in the repolarisation time, since no significant change in the QS interval was noted. As the QT top and QT end intervals showed consistent changes, the former may be used when there are difficulties in defining the end of the $T$ wave. No rate correction factor was required to obtain these QT interval changes because they were measured at a fixed heart rate. Transoesophageal atrial pacing was found to be a simple non-invasive method with few and relatively mild side effects. The method is well suited for drug studies requiring measurements at fixed heart rates.

This study was supported by grants from the Medical Society of Gothenburg and the Swedish National Association Against Heart and Chest Diseases.

\section{References}

1 Vaughan Williams EM. Classification of anti-arrhythmic drugs. In: Sandoe E, Flenstad-Jensen E, Olesen KH, eds. Symposium on cardiac arrhythmias. Södertälje: Astra, 1970: 449-69.

2 Prichard BNC. The use of beta adrenergic blocking drugs in cardiovascular disease. Scott Med F 1976; 21: 182-7.

3 Singh BN, Jewitt DE. Beta-adrenergic receptor blocking drugs in cardiac arrhythmias. Drugs 1974; 7: 426-61.

4 Åblad B, Borg KO, Carlsson E, Ek L, Johnsson G, Malmfors T, Regardh C-G. A survey of the pharmacological properties of metoprolol in animals and man. Acta Pharmacol Toxicol (Copenh) 1975; 36 (suppl 5): 7-23.

5 Fitzgerald JD. Beta blocking drugs as antiarrhythmic agents. Int f Clin Pharmacol Biopharm 1975; 11: 235-44.

6 Strauss HC, Bigger JT, Hoffman BF. Electrophysiological and beta-receptor blocking effects of MJ 1999 on dog and rabbit cardiac tissue. Circ Res 1970; 26: 661-78.

7 Singh BN, Vaughan Williams EM. A third class of antiarrhythmic action. Effects on atrial and ventricular intracellular potentials, and other pharmacological actions on cardiac muscle, of MJ 1999 and AH 3474. Br F Pharmacol 1970; 39: 675-87.

8 Edvardsson N, Hirsch I, Emanuelsson H, Pontén J, Olsson SB. Sotalol-induced delayed ventricular repolarization in man. Eur Heart f 1980; 1: 335-43.

9 Edvardsson N, Olsson SB. Effect of acute and chronic betareceptor blockade in man. Br Heart $\mathcal{f} 1981$; 45: 628-36.

10 Craemer J, Shennan A, Nathan A, Camm J. Effect of acute and chronic beta blockade with sotalol and propranolol on ventricular repolarisation. PACE 1985; 8: 310.

11 Benson DW, Sanford M, Dunnigan A, Benditt DG. Transesophageal atrial pacing threshold: role of interelectrode spacing, pulse width and catheter insertion depth. $\mathrm{Am} \mathcal{f}$ Cardiol 1984; 53: 63-7.

12 Raine AEG, Vaughan Williams EM. Electrophysiological basis for the contrasting prophylactic efficacy of acute and prolonged beta-blockade. Br Heart $\mathcal{F}$ 1978; 40 (suppl): 71-7.

13 Vaughan Williams EM, Raine AEG, Cabrera AA, Whyte JM The effects of prolonged beta-adrenoceptor blockade on heart weight and cardiac intracellular potentials in rabbits. Cardiovasc Res 1975; 9: 579-92.

14 Nathan AW, Hellestrand KJ, Bexton RS, Ward DE, Spurrell RAJ, Camm AJ. Electrophysiological effects of sotalo--just another beta blocker? Br Heart f 1982; 47: 515-20.

15 Raine AEG, Vaughan Williams EM. Adaptation to prolonged beta-blockade of rabbit atrial, Purkinje, and ventricular potentials, and of papillary muscle contraction. Circ Res 1981; 48: 804-12.

16 Fredlund BO, Olsson SB. Mätning av Q-T-tid, svärigheter, variabilitet, normalvärden och effekt av arbete. Acta Societatis Medicorum 1978; 87: 110.

17 Milne JR, Camm AJ, Ward DE, Spurrell RAJ. Effect of intravenous propranolol on QT interval. A new method of assessment. Br Heart f 1980; 43: 1-6.

18 Dick II M, Campbell RM, Jenkins JM. Thresholds for transesophageal atrial pacing. Cathet Cardiovasc Diagn 1984; 10: 507-13.

19 Jenkins JM, Dick M, Collins S, O'Neill W, Campbell RM, Wilber DJ. Use of the pill electrode for atrial transesophageal atrial pacing. PACE 1985; 8: 512-27.

20 Jenkins JM. Esophageal electrocardiography. In: Liebman J, Plonsey R, eds. New directions in pediatric electrocardiography. Amsterdam: Nartinus-Nijhoff (in press).

21 Edvardsson N, Bjerle P, Brorson L, et al. Reduction of chronic ventricular arrhythmias with the beta-blocker sotalol. A double blind study [Abstract]. Dan Med Bull 1983; 30 (suppl): 18.

22 Cobbe SM, Hoffiman E, Ritzenhoff A, Brachmann J, Kübler W, Senges J. Action of sotalol on potential re-entrant pathways and ventricular tachyarrhythmias in conscious dogs in the late postmyocardial infarction phase. Circulation 1983; 68: 865-71. 